\title{
فن العمارة في التراث العربي الإسلاهي
}

أ.م.د. باقر محمد هعفر الكرباسي/ كلية التربية الاساسية/ جامعة الكوفة م.د. هيام مرزة نور / معهد الفنوز الجميلة / بغداد / الكرخ

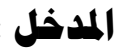

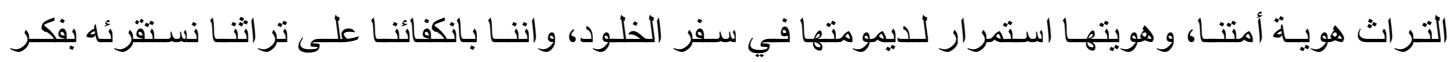

التحديث و عين التمحيص إنما نرنو إلى ماضِ ينبعث، ومجد يستيقظ، وإر ادة أمة عزمت على أن تستأنف عزتها وتستبقي

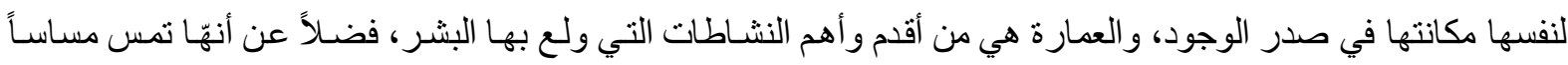
مباشـر اً الأسـاليب وطرق وحياة النـاس الثخصـية والعامـة ، فهي تنظم سكناهم وأمـاكن عملهم و إنتاجهم و تخطط مـدنهم وقر اهم، فقد كـان للفنـون بصـورة عامـة وللفن المعدـاري بصـورة خاصــة مكانـة كبيـرة عند حكـام المسلمين و أمـر ائهم وملوكهم، وكان الفنانون على اختلاف جنسياتهم يظفرون بالتقدير والمكافأة من الحكام الذين يحلو لهم استغلال مو اهب هؤ لاء الفنانين في تشييد المباني وتزيينها وزخرفتها وتأثيثها، منفقين عليها المـال بكل سخاء وكرم ، فالمسـاجد و القصور و المدارس ودور الثفاء و القلاع الحصينة وغير هـا كانت كلها تثّيديد بـأمر هؤل لاء الحكام وتحت إنشر افهم فيعنى بزخرفتها وجمالها لتحمل اسمهم في الحياة وتضم رفاتهم في الممات احيانـاً ، هكذا كـان فن البناء دوماً في خدمـة الأمر اء و والسـلاطين

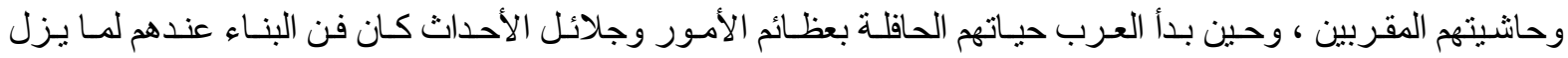
وليداً، فلم يكن أي فن بناء ظاهر الآ في البقاع الخصبة التي كان يسكنها شعب يعيش في رخاءو واستقرار كاليمن . وبعد أن نََّّ للعرب الاستقر ار في البلاد التي رفعوا فوقها رايتهم توجهوا بكل همـة ونشـاط إلى الناحيـة العمر انية، فاستعانوا برجال الفن والصنعة من أهل البلاد التي خضعت لحكمهم وبرجال فنيين من البلاد التي بقيت خـارج هذا الحكم،

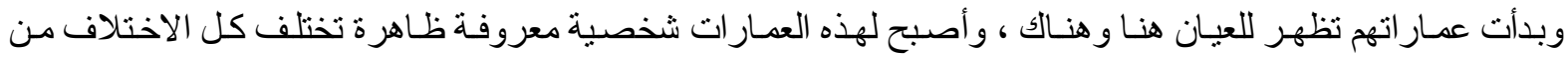
حيث الأسلوب والطراز عن تلك التي وجدو ها قائمة في البلاد التي نمَّ لهم فتحها.

\section{المبحث الأول - تطور فن العهارة العربية الإسلاهيية}

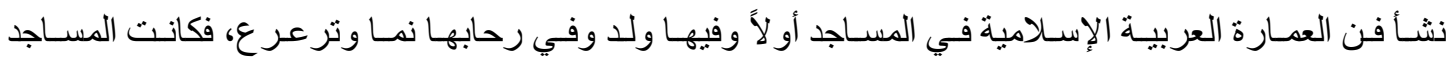

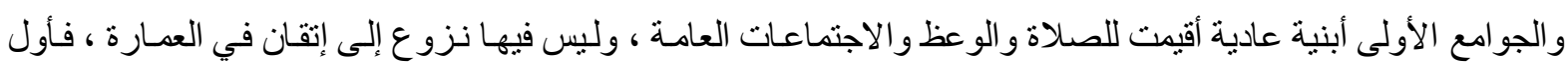

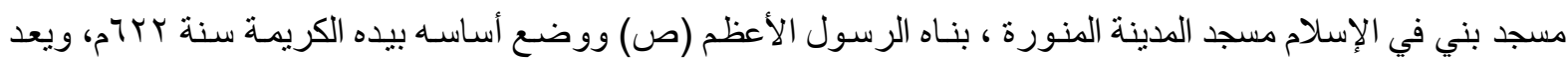
النموذج الأول لسائر المساجد الأخرى، وكان هذا المسجد مسـاحة من الأرض مربعة الثكل ، تحبط بها جدران من الآجر و الحجر، وكان هنـاك سقف على جز ء من أجزاء هذا المربع سقيفة صنعت من جريد النخل.( (1). وفي منّل هذا البنـاء

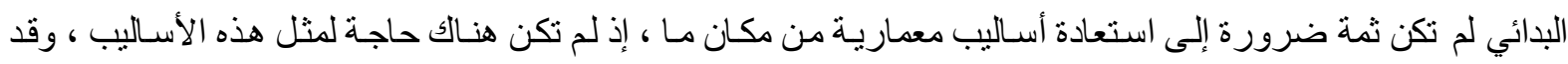

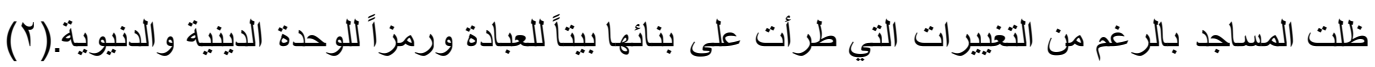
انتقل العرب بعد ذللك من القناعة بالضروري اللازم إلى الأبنية الضخمة الفـاخرة انتقالاً سريعاً، فلم يمضِ على وفاة النبي (ص) عشرون سنة حتى أعيد بنـاء مسجده بالمدينـة ، و أقيمت لـه جدران ودعائم من الحجر ، وبعد سنين قليلة

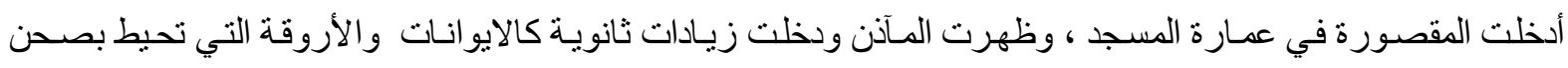

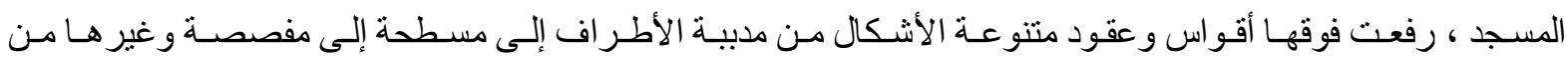

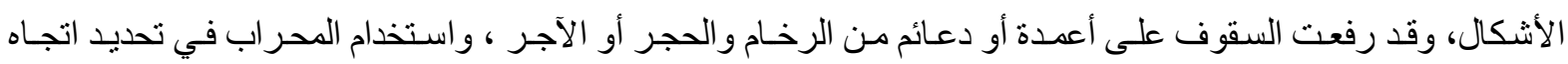


القبلة ، فقي هذا الزمن القصير تطورت عمـارة المسـاجد حتى أصبحت تشمل جميع المظــاهر الرئيسـة الهامـة في بنـاء (r). (المساجد)

اتخذ المسلمون القبة عنصر اً مميز اً لأبنيـة المسـاجد ، وهذا مـا قـال عنه بعض الباحثين في فن العمارة ووصفوه

بـالر أي الصـائب ،يقول الباحث شـريف يوسف :(لقد اظهر المسلمون رأيـاً صـائباً في اتخـاذ القبـة عنصـراً مميز اً لأبنيـة

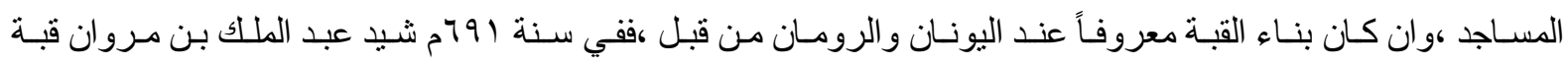

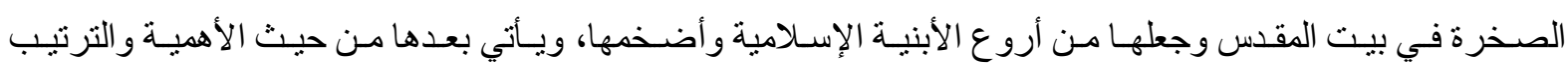
التاريخي المسجد الجامع الأموي في دمشق، ومما يمتاز بـه هذا المسجد من حيث الفن المعمـاري الأقواس التي تشبه حدوة

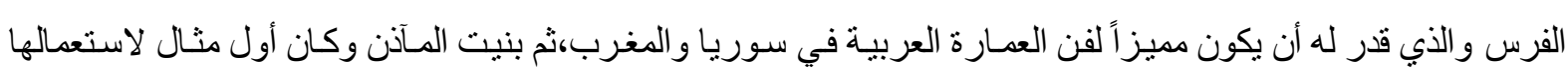

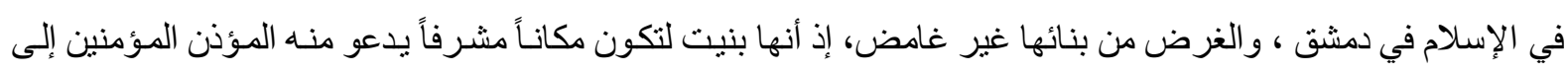

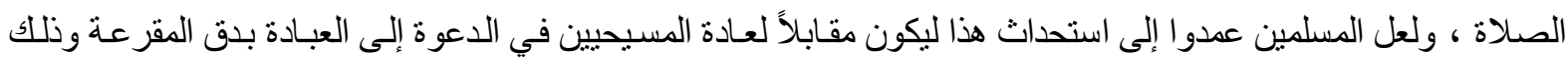

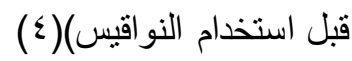

ويضيف الباحث شريف يوسف قائلاً :( و هنالك فوق الظواهر المعماريـة التي ذكرناهـا عناصر أخرى مميزة

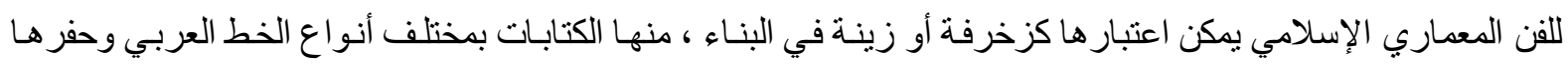

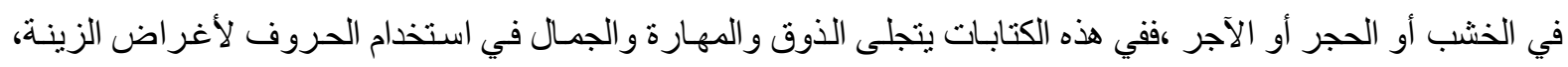

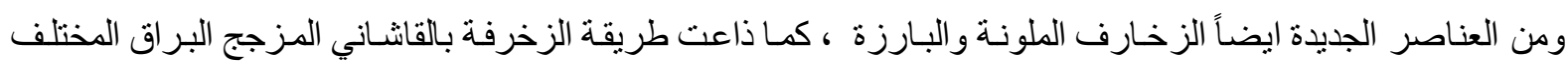

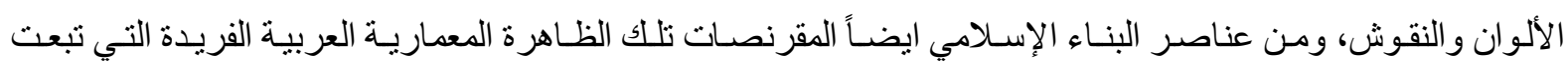

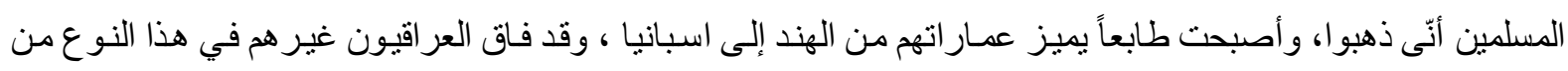

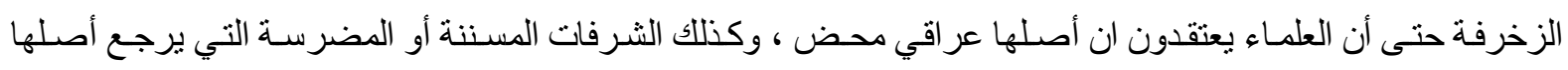
إلى طراز البناء العراقي الآشوري والبابلي)(0)

ولو رجعنـا إلى العرب وتأثر هم بالحضـار ات والمدنيات لو جدنا أنهم تأثروا بحضـار ات ومدنيات البلاد التي

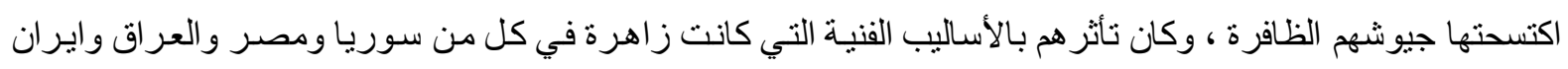

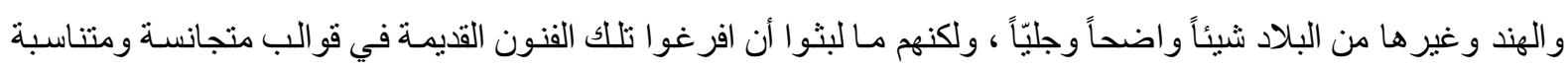

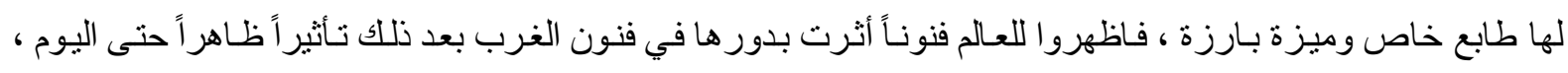

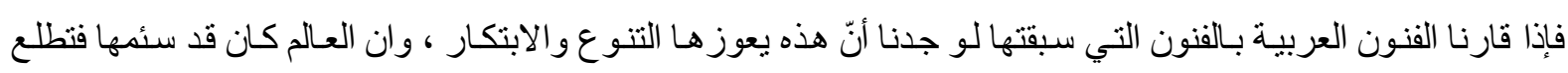

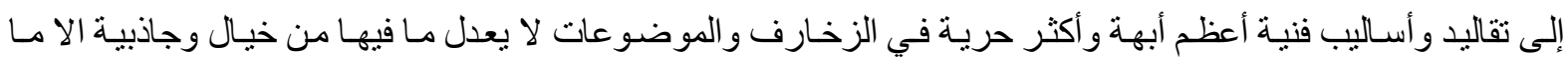

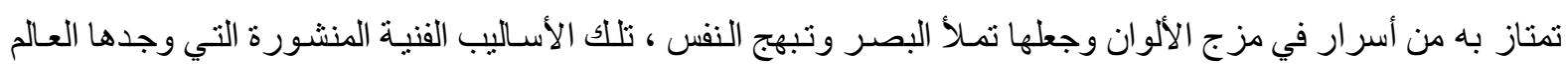

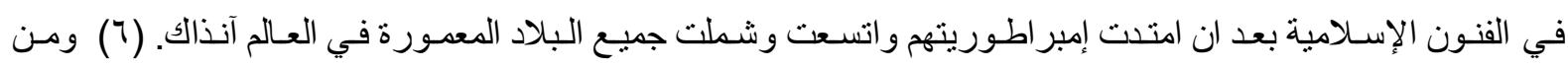

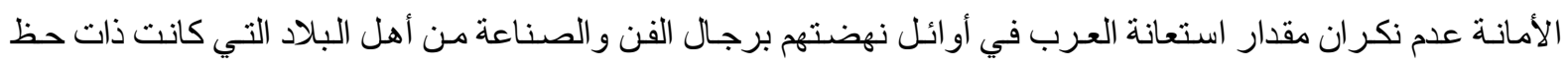
و افر من الحضـارة في ذللك العهد، فالعمـار ات الإسـلامية القائمـة في العـالم الإسـلامي الممتد من الصين شـرقاً إلى الأندلس

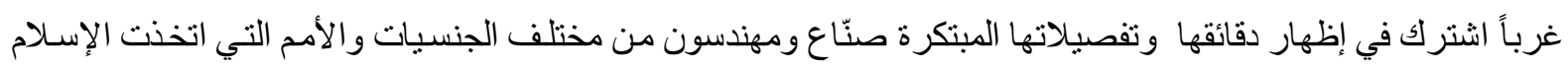

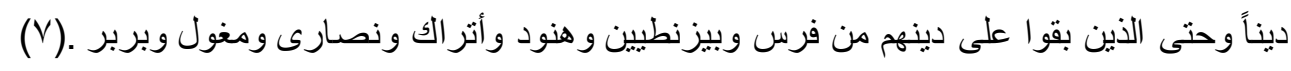


إن كل منصف لا يستطيع ان ينكر فضل علمـاء الغرب في دراسـة الفن العربي الإسـلامي ، فقد عني الغربيون

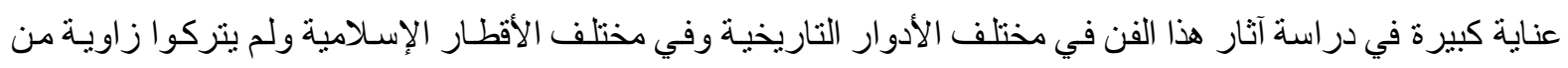

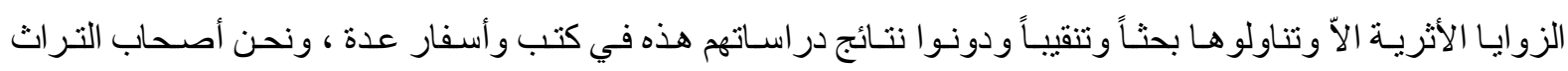

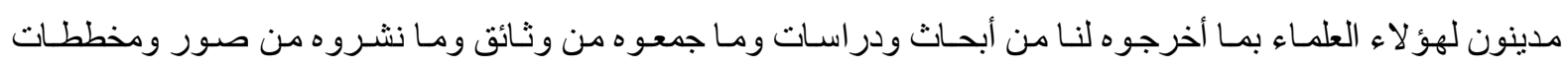
ورسومات ، فمن الواجب الاعتر اف بفضلهم وتقدير مجهودهم الكبير وتضـحيتهم مـن مـال ووقت في التأليف والتنقيح و الإخر اج والطبع .

\section{دراسة فن العمارة الإسلاميية :-}

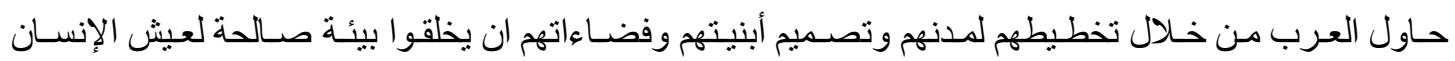

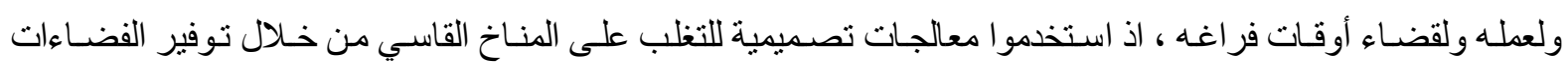

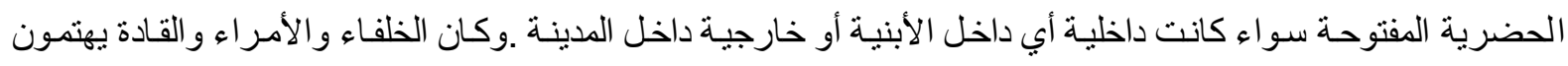

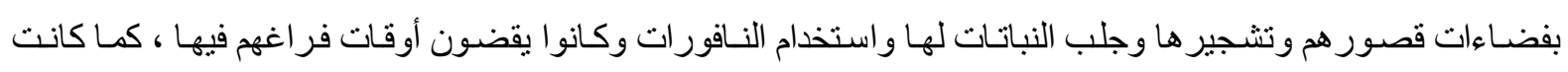

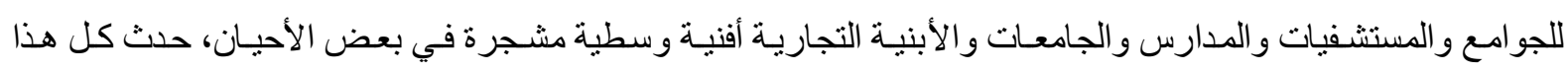
عندما بدأ الطر از الإسلامي يظهر للعيان وأخذ المسلمون يجمعون شتى الطرز المعماريـة القديمـة ويطبعونها بطـابع دينهم الجديد ويظهرونها للعـالم فنـاً معمارياً جديداً متميزاً عن غيره من الفنون المعماريـة المعروفة في العـالم ومن خـلال بحثنـا

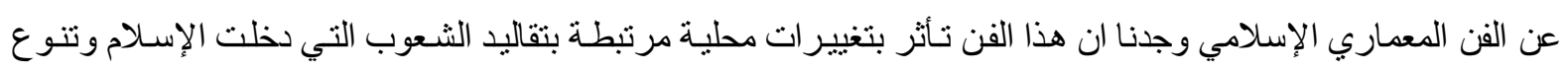
بتنوع المواد الإنشائية الموجودة في كل بلد من البلدان الإسـامية ،كمـا تـأثر بعدوى الجوار للأمم التي لم يستطع الإسـلام

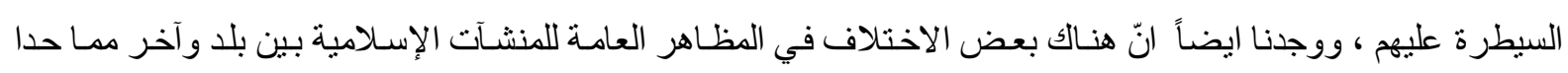

بالعلماء إلى تقسيم الفن المعماري الإسلامي إلى مدارس عدة ، وقد حددّ العالم (هـ. سلادان )هذه المدارس بما يأتي :

$$
\text { أ- - م المدرسة السورية - المصرية }
$$

ب- المدرسة المغربية وتشمل تونس والجزائر والمغرب واسبانبا وصقلية.

ح- الدرسة الفارسية وتضم بلاد الر افدين وايران

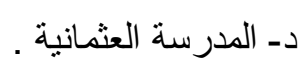

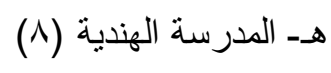

ان هذا التقسيم حسبما يقول الباحث شريف يوسف: (لا يعني وجود حدود حقيقية بين مدرسة وأخرى ، و علينـا

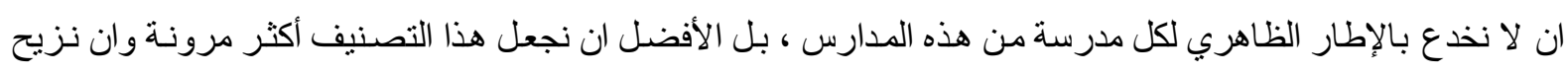

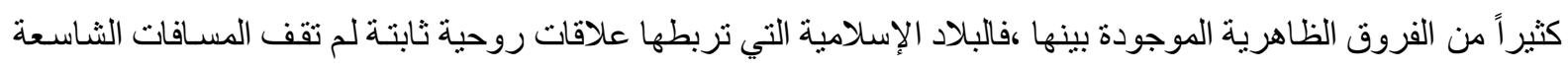

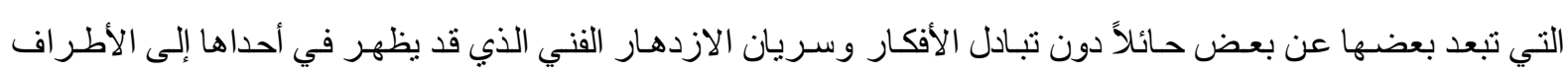

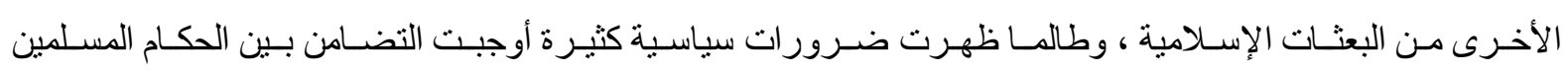

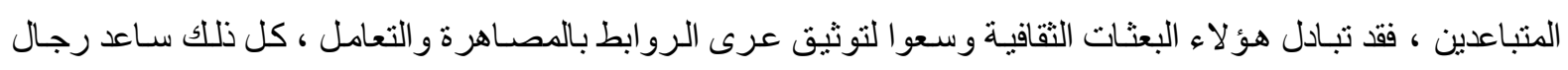
الفن على الانتقال من بلد إلى آخر لتبادل الصيغ الفنية والتباهي في التفوق الفني عند كل منها ـ (9.

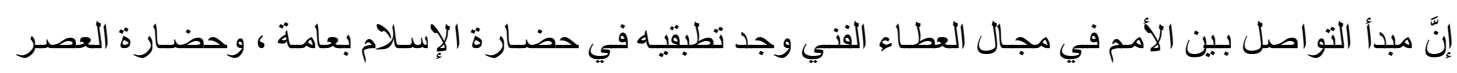

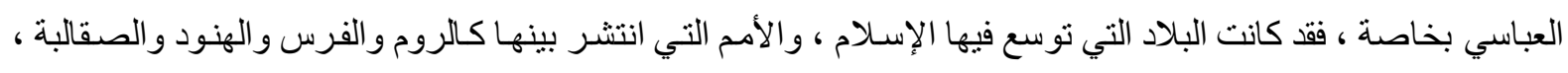

\section{$-r$ r.}


ذات تراث فني سابق ، فأخذ عنهـا المجتمع الجديد في حدود حاجاته و استعداداته وقيمِهِ لِينشـأ عن هذا التناقي وعن طبيعـة التواصل خصوصيات فنية إسلامية برزت في مجالات العمارة والزخرفة والخط والموسيقى والغناء والرسم .

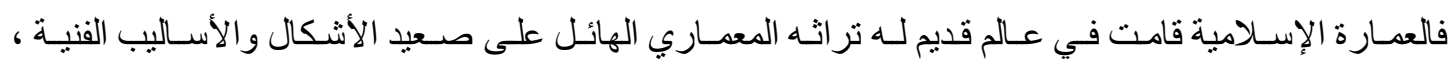

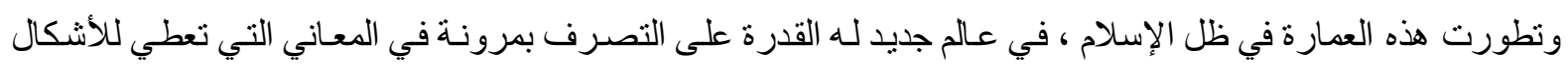

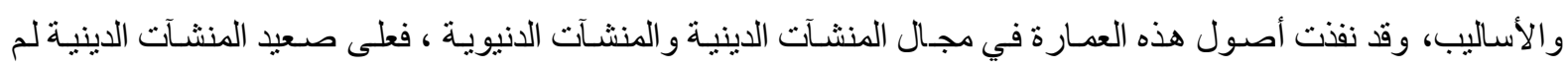

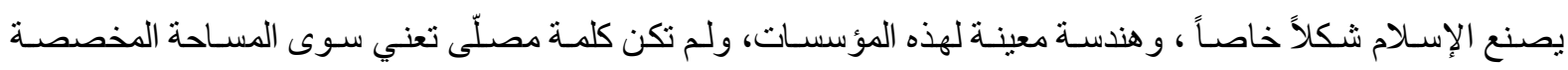

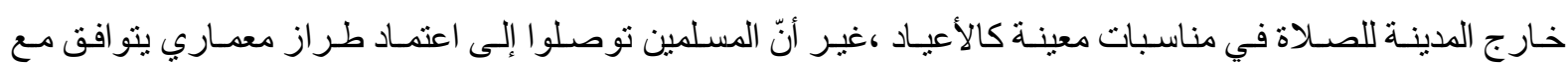

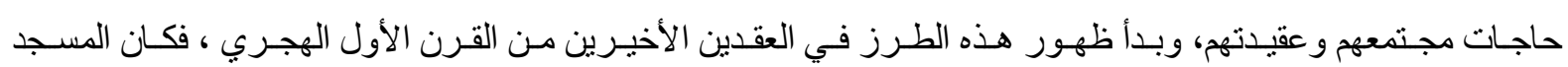

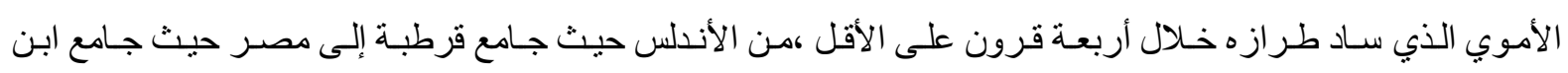

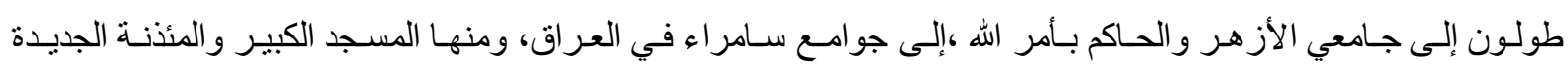

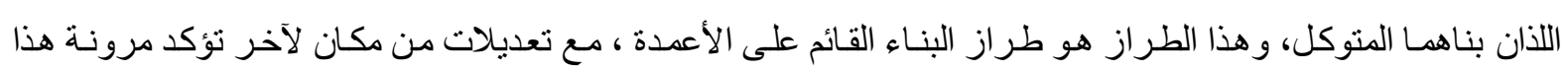

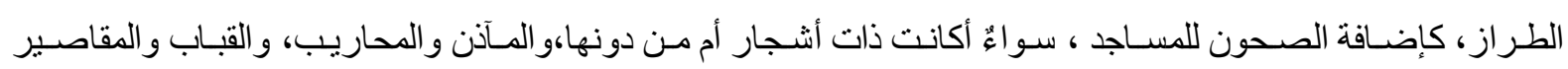

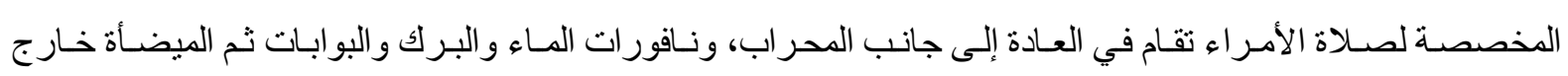

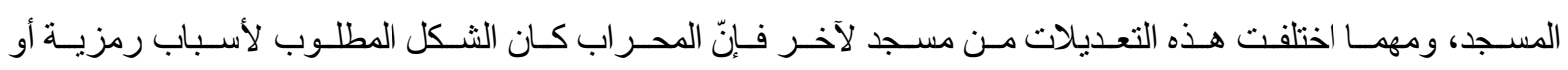
شعائرية(·) (1)

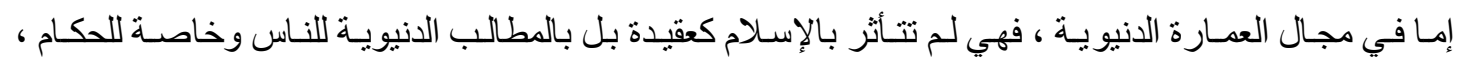

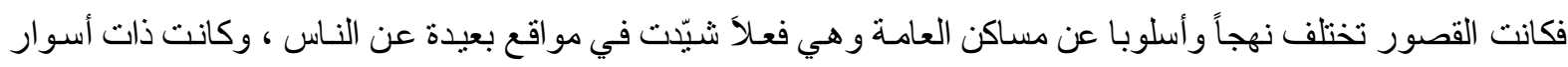

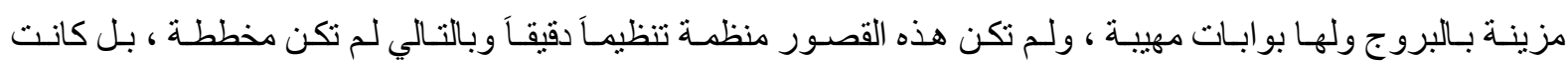

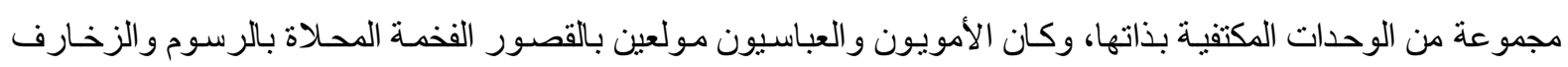

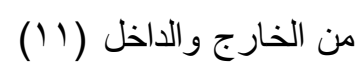

فقد بنـى الأمويون قصـر المشتى وقصـر الحير وقصر عمره وقصـر المفجر في الشـام والأردن ، التي ضمت

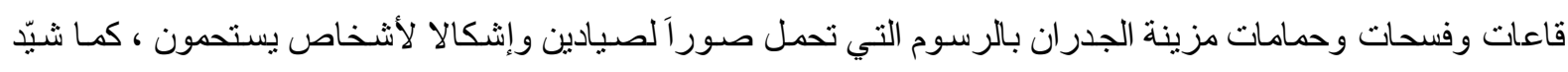

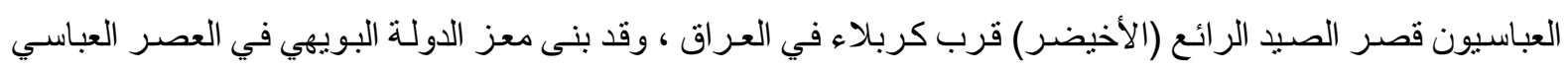

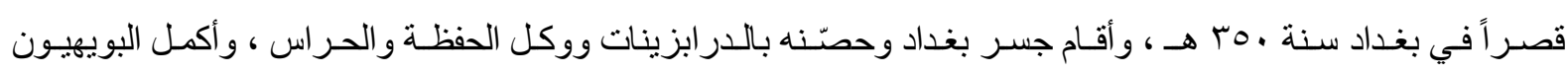

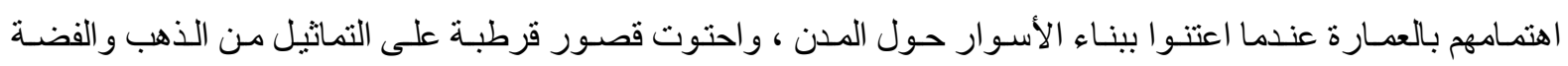

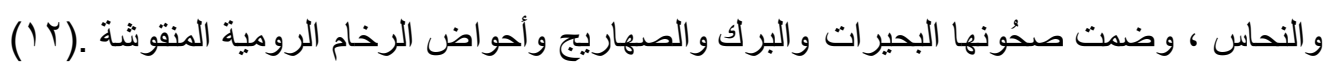
كمـا برزت مظـاهر الأبهـة والفخامـة على سـائر المنشـآت المدنيـة في العصـر العباسـي ، كالمدارس والـكاكين

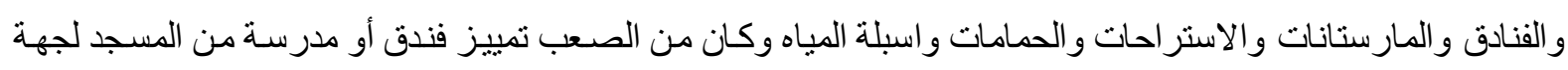

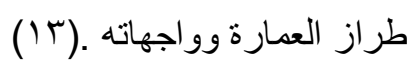

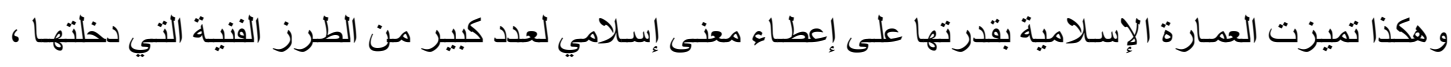
كما بدت العمارة الإسلامية ذات صيغة دنيوية في إطار العصور الوسطى الذي كان يظهر انه يدور حول محور الدين . 


\section{المبحث الثاني - الأدوار التاريخية التي هرَّ بها فن العمارة الإسلاهية}

قسم العلماء الأدوار التي مََّّ بها الفن المعماري الإسلامي إلى أربع فترات أساسية كبرى هي :

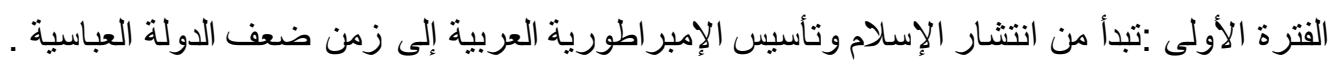
الفترة الثنانية : استمرت زهاء مئتين وخمسين سنة وفيها كانت الخلافة الأمويـة في الأندلس و الخلافة الفاطمية في مصر في أوج عظمتها .

الفترة الثالثة: امندت من القرن الثالث عشر الميلادي إلى القرن الخامس عشر وفيها انحلت سلطة الخلفاء في بغداد.

الفترة الرابعة : التي دامت نحو أربعة قرون توحت فيها البلاد الإسلامية تحت الحكم العثماني .( ( )

فقي الفترة الأولى كـان مسجد الرسـول محمد (ص) في المدينـة المنـورة النمـوذج الأول لبنـاء المســاجد في المـدن

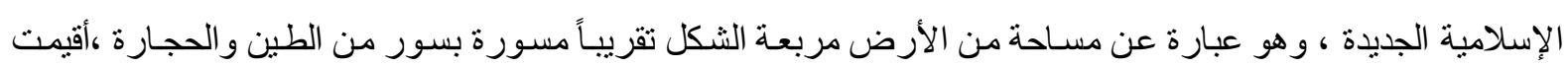

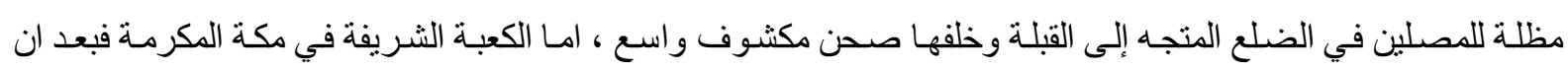

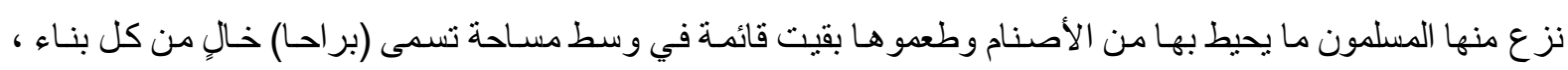
وكانت دور قريش متو اضعة البناء شيدت من حجارة مكة (الدبش) ذات دور واحد ، وأبو ابها شـار عة إلى الكعبة ، و وعندما

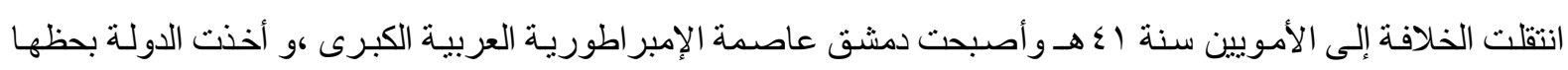

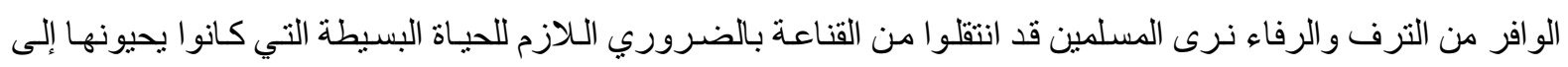

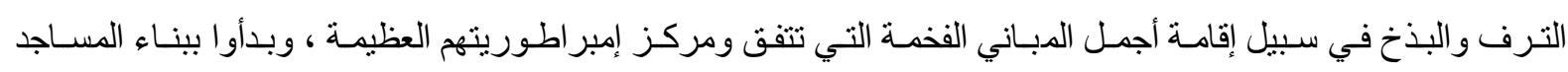

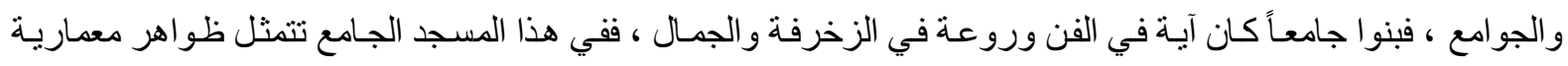

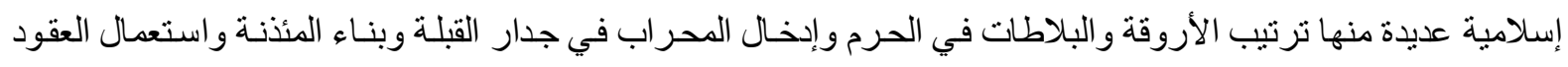

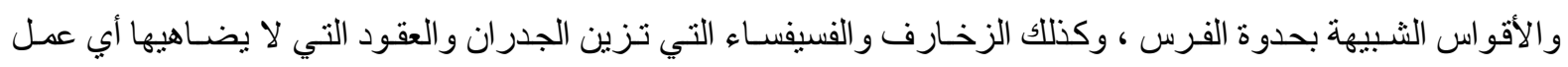
مماتل عند الرومان.(10)

ولم يقتصر اهتمام الخلفاء الأمويين على بنـاء المسـاجد والجوامع في مختلف المدن الإسـامية بل أر اد بعضهم ان

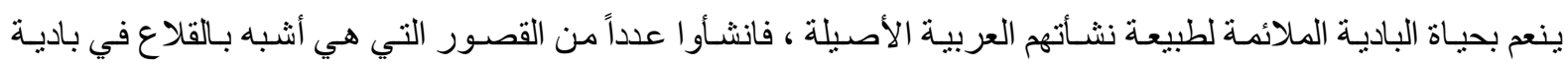

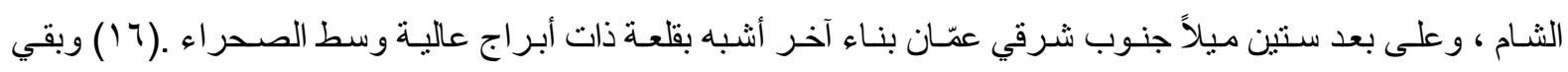

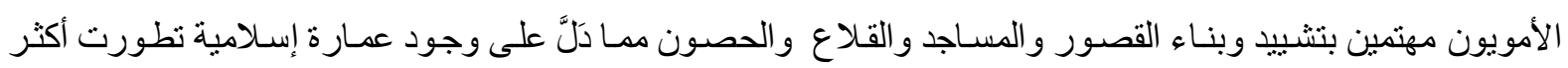
من السابق .

وفي عصر بني العباس و الذي بدأ بسقوط الدولـة الأمويـة سنـة بـا هـ ، يذكر فيـه المؤرخون و البـاحثون مـا أقدم

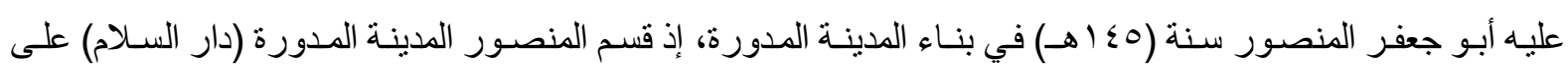

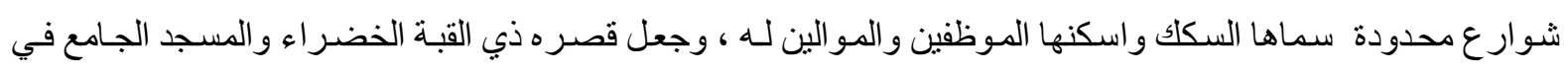

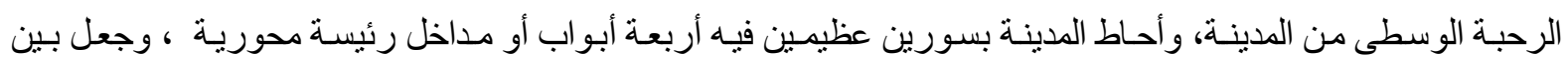

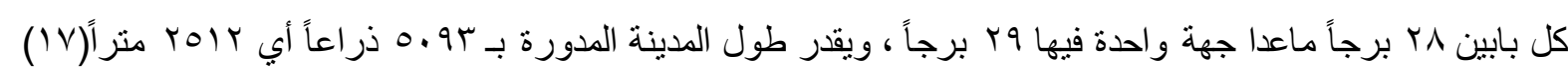
اما في مدينة سامر اء أيام ازدهار ها كانت سيدة مدن العالم ، تقع سـامر اء على بعد . با كم شمال بغداد ، بناهـا

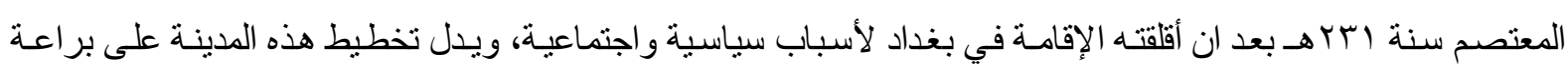


فائقة في هندسة المدن وتخطيطها ففيه كثير من الابتكارات في تنظيم الشوار ع وتوزيع المسـاكن وتنسيق الأبنية العامـة

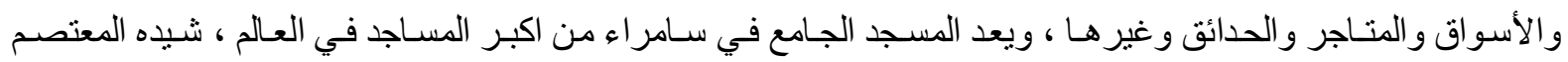

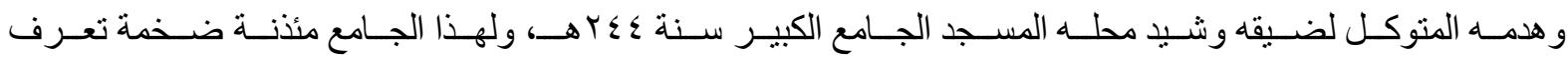

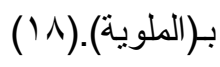

وكـان من نتائج اتساع الدولـة العباسية وامتداد نفوذهـا إلى أغلب بقاع المعدورة ان تدفقت الخيرات على بغداد

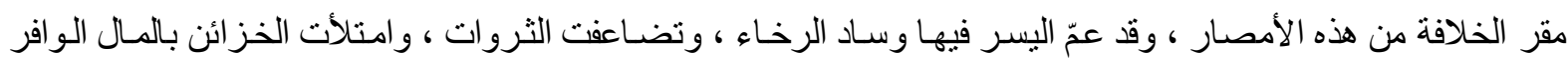
فانصرف الخلفاء والأمر اء إلى تتبييد الدور الجميلة والقصور المنمقة وبالغوا في تجميلها وتزيينها بكل مـا وهبوا من ذوق

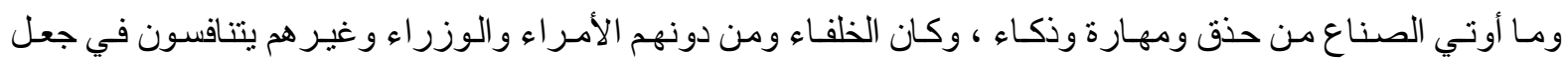
قصور هم ودور هم آيـة في الفن ومثناً في روعة البنـاء وجمـال المنظر ، و القصـور متعددة في بغداد تعاقب على بنائهـا

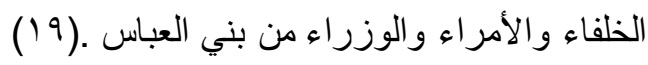

لقد بنيت الحضارة الإسلامية على مبدأ (الوسطية) ، و اذا كانت الوسطية هي المبدأ الذبي ينظم حياة الإنسـان فلا

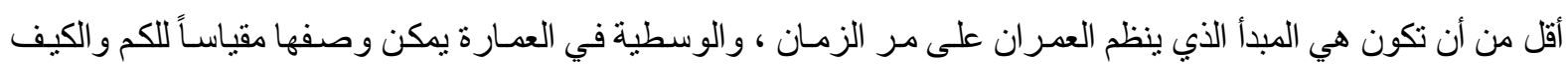

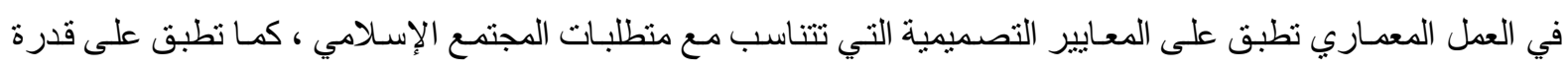

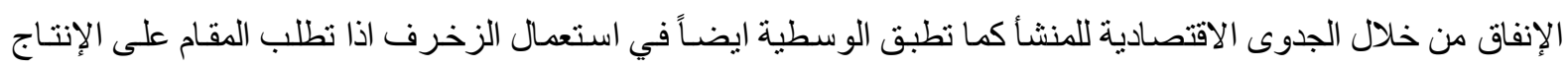

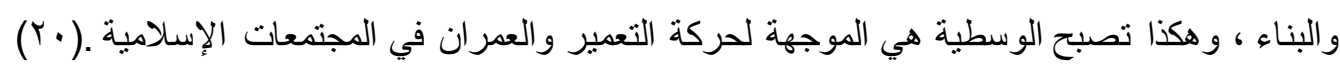
إنّ بناء الفكر المعماري الإسـامي هو في واقع الأمر حركة ثقافيـة لابد وأن تؤثر على العامـة من المجتمع كمـا

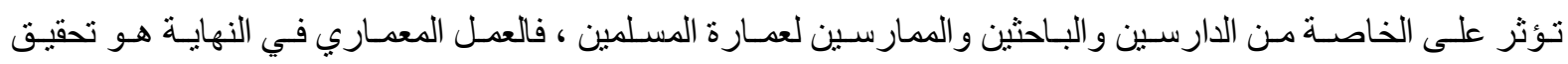

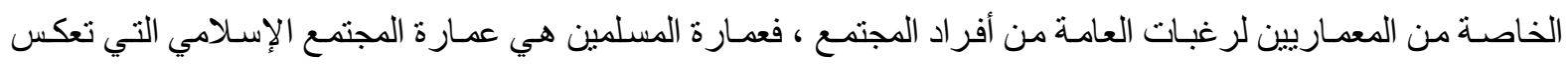

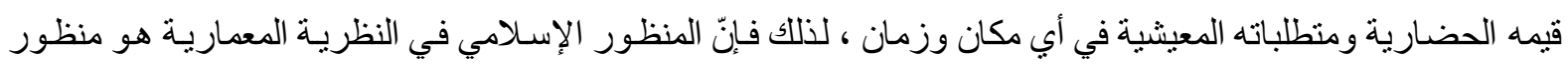

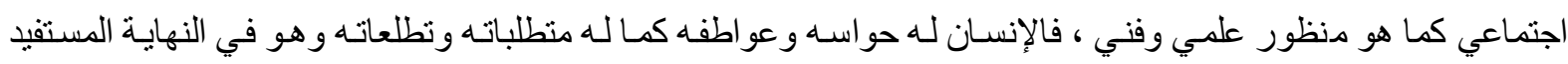

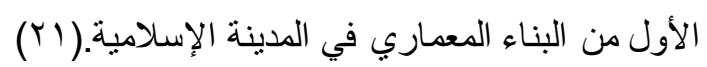

لقد كـان لاستمر ار المـد الحضـاري الغربي في العـالم الإسـلامي أثره في قلب الموازين الحضـارية للمجتمعـات

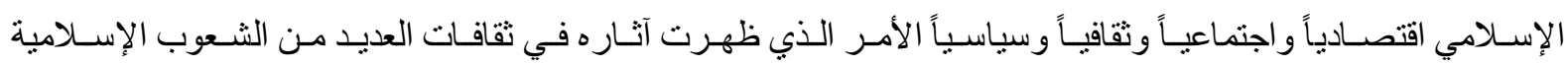

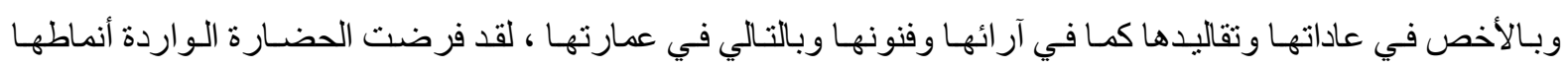

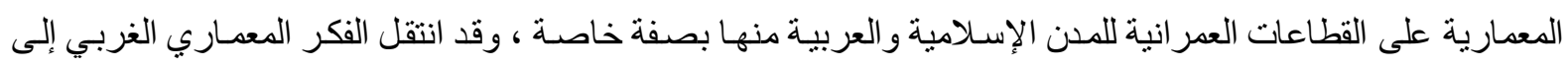

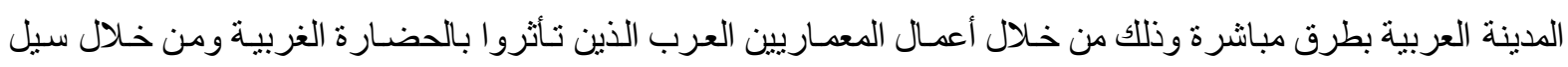

الإصدارات المعمارية من الكتب والمجلات الوافدة والتي غزت الساحة المعمارية الإسلامية والعربية منها.

\section{خاتمة البمث: -}

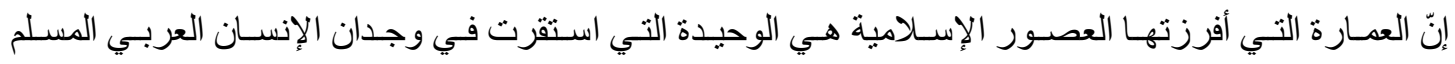

و أصبحت العقيدة هي الموجه الأساس لمكوناتها الداخلية التي انعكست على تشكيلاتها الخارجيـة ، فكانت انعكاسـاً واضحاً

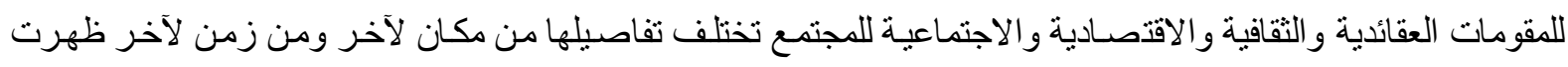

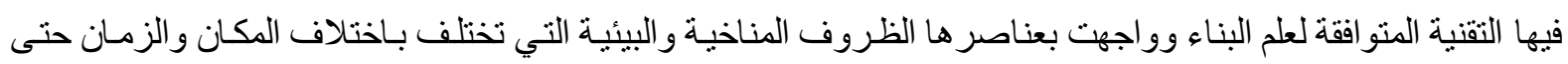


أصسبحت عمـارة العصـور الإسـلامية مرجعـاً للابتكـار و الاقتبـاس ، فهـي مـن الـاخل تتفق مـع القيم والرغبـات الفرديـة للمستعمل اما من الخارج فهي تتفق مع القيم والرغبات العامـة للمجتمع الذي يتحرك خارجها ويتعايش معها ، لقد ظهرت العمارة الإسـلامية غنيـة بمكملاتها التشكيلية والجمالية التي تعتمد على الوحدة الزخرفيـة و العلاقات الهندسية التابعـة مـن الأسس البنائية والثقنية الحرفية والمواد الإنثائية .

\section{هواهش البـث : nمث}

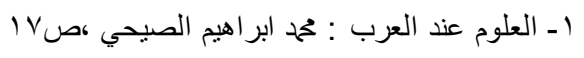

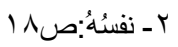

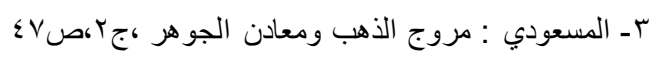

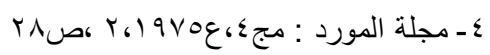

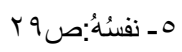

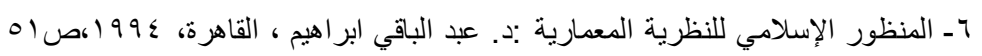

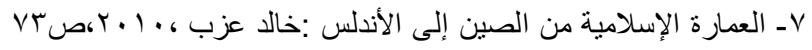

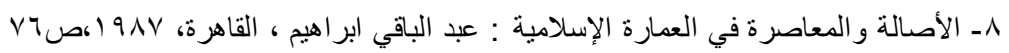

9 - مجلة المورد: المرجع السابق صالب

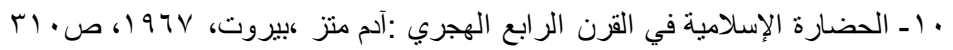

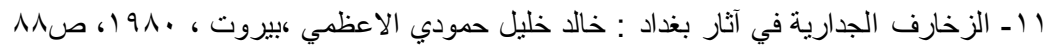

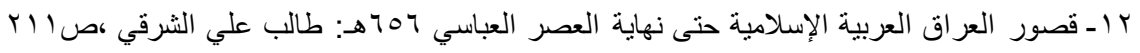

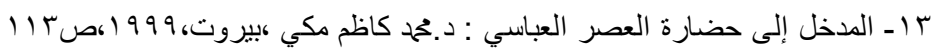

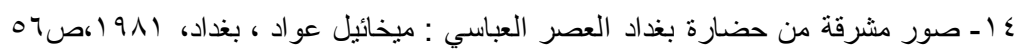

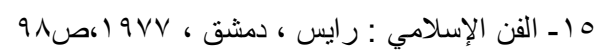

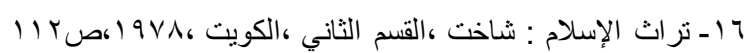

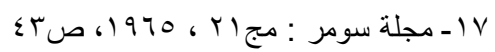

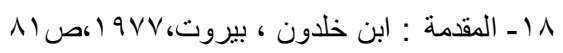

9 1 - بغداد تاريخها و آثار ها : بشير فرنسيس ، بغداد 909 (،صس كـ

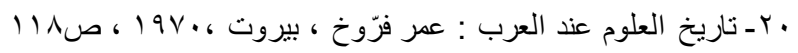

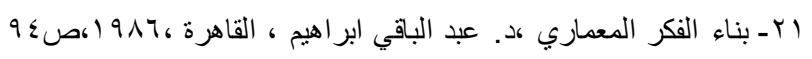

هصادر البحث وهراجعهُ

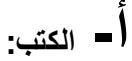

ا - الأعظمي ، خالد خليل حمودي:

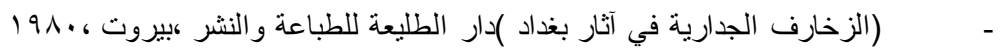

r- ابر اهيم ، عبد الباقي (الدكتور):

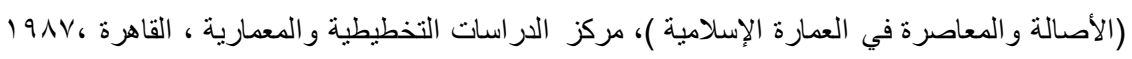

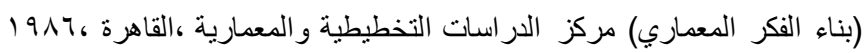

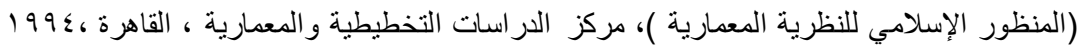

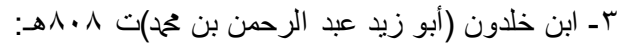

\section{- rY .}


l المقدمة ـ دار إحياء التراث العربي ، بيروت / لبنان ط؛

ع - رايس:

(الفن الإسلامي) ، ترجمة الأصبحي ،المجلس الأعلى لرعاية الفنون و الآداب ،دمشق، وVV

هـ شاخت:

(تراث الإسلام) ،القسم الثاني ، سلسلة عالم المعرفة ع 1 $19 \vee 1$ الكويت ،

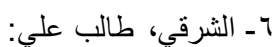

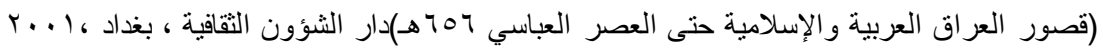

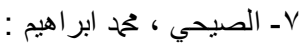

(العلوم عند العرب )، مكتبة نهضة مصر ، القاهرة سلسلة حضارة أجدادك العرب ،عا(،د.ت

人

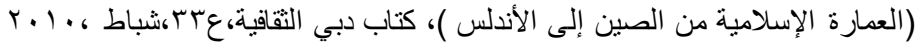

9 - عو اد ، ميخائيل :

(صور مشرقة من حضارة بغداد في العصر العباسي)، منشورات وزارة الإعلام ، بغداد، 1919

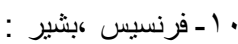

(بغداد تاريخها و آثار ها ) ،مطبعة الر ابطة ،بغداد ، 1909

|

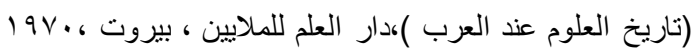

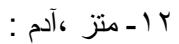

(الحضارة الإسلامية في القرن الرابع الهجري )، تعريب :محمد عبد الهادي أبو ريده بيروت ،ط؛، لو 197

rا ـ المسعودي (أبو الحسن علي بن الحسين )تح ؟ آهـ:

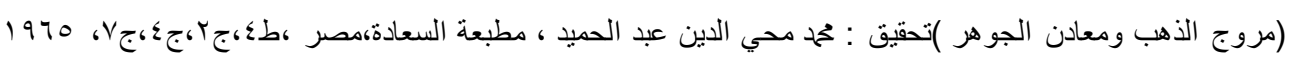

ع ا - مكي ، حمح كاظم (الدكتور):

(المدخل إلى حضارة العصر العباسي)دار الزهر اءهبيروت ، لبنان ،طب، 1999

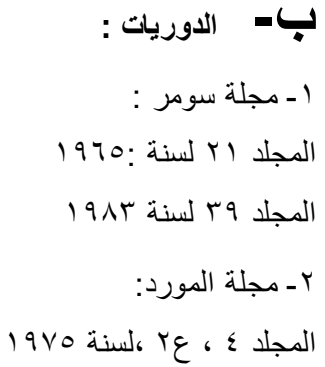

